\title{
Rac1 Controls the Formation of Midline Commissures and the Competency of Tangential Migration in Ventral Telencephalic Neurons
}

\author{
Lei Chen, ${ }^{1,4}$ Guanghong Liao, ${ }^{2}$ Ronald R. Waclaw, ${ }^{2,4}$ Kevin A. Burns, ${ }^{2,4}$ Diana Linquist, ${ }^{3}$ Kenneth Campbell, ${ }^{2,4}$ \\ Yi Zheng, ${ }^{1,4 *}$ and Chia-Yi Kuan ${ }^{2,4 *}$ \\ Divisions of ${ }^{1}$ Experimental Hematology and ${ }^{2}$ Developmental Biology, ${ }^{3}$ Imaging Research Center, Cincinnati Children's Hospital Medical Center, and \\ ${ }^{4}$ Molecular and Developmental Biology Graduate Program, University of Cincinnati College of Medicine, Cincinnati, Ohio 45229
}

\begin{abstract}
Previous studies using dominant-mutant constructs have implicated Rac1 GTPase in neuritogenesis and neuronal migration. However, overexpression of dominant mutants generally blocks Rho-GTPase activity; thus, it may not reveal the specific or physiological functions of Racl. To address this issue, we have applied a conditional gene-targeting strategy, using Foxg1-Cre mice to delete Racl in the ventricular zone (VZ) of telencephalon and Dlx $5 / 6$-Cre-IRES (internal ribosomal entry site)-EGFP (enhanced green fluorescent protein) (Dlx5/6-CIE) in the subventricular zone (SVZ) of ventral telencephalon, respectively. Surprisingly, the deletion of Rac1 in VZ progenitors did not prevent axonal outgrowth of telencephalic neurons. However, the anterior commissure was absent, and the corpus callosal as well as hippocampal commissural axons failed to cross the midline in Rac1/Foxg1-Cre knock-out embryos. The thalamocortical and corticothalamic axons also showed defasciculation or projection defects. These results suggest that Racl controls axon guidance rather than neuritogenesis. In addition, although Rac1/Foxg1-Cre knock-out embryos showed delayed radial migration of cortical projection neurons and severe impairment of tangential migration by the ventral telencephalon-derived interneurons, deletion of Racl in the SVZ by Dlx5/6-CIE mice produced no discernible defects in tangential migration. These contrasting effects of Racl deletion on tangential migration suggest that Racl is dispensable for cellular motility per se during neuronal migration. Together, these results underscore the challenge of deciphering the biological functions of Rac1, and Rho-GTPases in general, during mammalian brain development. Moreover, they indicate that Racl has a critical role in axon guidance and in acquisition of migratory competency during differentiation of the progenitors for the ventral telencephalon-derived interneurons.
\end{abstract}

Key words: Rho GTPases; Rac1; gene targeting; neuritogenesis; neuronal migration; axon guidance; neuronal differentiation

\section{Introduction}

Rac1 belongs to the Rho family of Ras-like small GTP-binding proteins that control many important cellular functions including actin polymerization, microtubule stability, migration, and cell polarity (Ridley et al., 1992; Jaffe and Hall, 2005). Like all Rho-GTPases, Rac acts as a binary switch cycling between an inactive GDP-bound form and an active GTP-bound state (Bishop and Hall, 2000). This cycling process is tightly regulated by multiple guanine nucleotide exchange factors (GEFs), the GTPase-activating proteins (GAPs), and the guanine nucleotide dissociation inhibitors (GDIs) (Zheng, 2001; Moon and Zheng, 2003). Rac1 shares sequence homology with Rac2 and Rac3, forming the Rac subfamily of Rho-GTPases. Although Rac1 is widely expressed in many tissues, Rac2 is restricted in the hema-

\footnotetext{
Received Aug. 13, 2006; revised March 5, 2007; accepted March 6, 2007.

This work was supported by National Institutes of Health Grants NS44315 (C.-Y. K.) and CA105117 and GM60523

(Y.Z.). We thank Scott Dunn for excellent technical assistance with magnetic resonance imaging.

*Y.Z. and C.-Y.K. are corresponding senior authors.

Correspondence should be addressed to either Dr. Chia-Yi Kuan or Dr. Yi Zheng, Cincinnati Children's Hospital

Medical Center, 3333 Burnet Avenue, Cincinnati, 0H 45229. E-mail: alex.kuan@cchmc.org or yi.zheng@cchmc.org. DOI:10.1523/JNEUROSCI.3509-06.2007

Copyright $\odot 2007$ Society for Neuroscience $\quad$ 0270-6474/07/273884-10\$15.00/0
}

topoietic system, and Rac3 is highly enriched in the nervous system (Haataja et al., 1997; Malosio et al., 1997).

The functions of Rho-GTPases have been studied mostly by expressing dominant-negative or constitutive-active mutants in cells or transgenic animals, which suggested a critical role of Rac1 in neuritogenesis and neuronal migration (Govek et al., 2005). However, this approach is compromised by the abundant crosstalk between different subfamilies of Rho-GTPases. For example, the dominant-negative mutant of Racl works by sequestering the upstream GEFs, but there are $>70$ GEFs in the genome, and many are known to regulate multiple Rho-GTPases (Etienne-Manneville and Hall, 2002). Moreover, because overexpression of dominant-negative mutant is needed to block the endogenous Racl activity because of its noncatalytic nature, the excessive amount of Racl mutant and GEF-impounding may further inhibit the activity of multiple Rho-GTPases, including Rac3, Cdc42, and RhoG. Conversely, the constitutively GTPbound Rac1 mutant could activate downstream effectors normally engaged by Cdc42 (Sarner et al., 2000; Aoki et al., 2004). Furthermore, because continuous GTP-binding/GTP-hydrolysis cycling is required for effective signaling flow of Rho-GTPases, expression of constitutively GTP-bound Rac1 often causes simi- 
lar phenotypes like dominant-negative mutants (Woo and Gomez, 2006). Thus, it is necessary to compare the phenotypes of dominant-mutant expression with those of targeted disruption of individual Rho-GTPases to deduce its biological functions (Wang and Zheng, 2007). However, the germline deletion of Racl causes embryonic lethality in gastrulation, precluding the analysis of Racl functions in brain development (Sugihara et al., 1998). In contrast, the germline deletion of Rac3 causes no obvious brain malformations, suggesting that Racl either has a predominant role or redundant functions with Rac3 in neural development (Corbetta et al., 2005).

To assess the biological functions of Racl in mammalian brain development, we have applied a conditional gene-targeting strategy using Foxg1-Cre mice to delete Racl in the ventricular zone (VZ) of the entire telencephalon (Hebert and McConnell, 2000) and Dlx5/6-Cre-internal ribosomal entry site (IRES)-enhanced green fluorescent protein (EGFP) mice (Dlx5/6-CIE) to delete Rac1 in the subventricular zone (SVZ) of ventral telencephalon (Stenman et al., 2003). Our analysis indicates that, in contrast to previous studies using dominant-negative mutant, Racl is not essential for neuritogenesis but has important functions in axonal projection. Moreover, Racl has a unique role in the ventral telencephalic progenitors for establishing the competency of subsequent migration by the olfactory and cortical interneurons.

\section{Materials and Methods}

Generation of Foxg1-Cre- and Dlx5/6-CIE-directed conditional Rac1 mutant mice. Rac1 $1^{\text {flox/flox }}$ mice were crossbred with the Foxg $1{ }^{\mathrm{Cre} /+}$ mice to derive the Rac1 ${ }^{\text {flox/flox}}$; Foxg1 ${ }^{\text {Cre/+ }}$ genotype. The genotype of Racl and Foxg1 alleles was performed by PCR as described previously (Hebert and McConnell, 2000; Gu et al., 2003). The primer sequences for the Rac1 allele are as follows: (1) TCCAATCTGTGCTGCCCATC; (2) CAGAGCTCGAATCCAGAAACTAGTA; and (3) GATGCTTCTAGGGGTGAGCC. The PCR product of wild-type ( $\mathrm{Rac1}{ }^{\mathrm{WT}}$ ), floxed $\left(\operatorname{Racl}^{\text {flox }}\right)$, and recombined-floxed $\left(\operatorname{Racl}^{\Delta \text { flox }}\right)$ allele of Rac1 is $115 \mathrm{bp}$, 242 bp, and 140 bp long, respectively (see Fig. 1). The targeted Foxg1 Cre allele was PCR genotyped for Cre (Hebert and McConnell, 2000). The

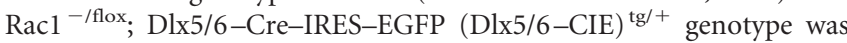
derived by cross-breeding of Rac1 ${ }^{\text {flox/flox }}$ mice with $\mathrm{Racl}^{+/-}$Dlx5/6$\mathrm{CIE}^{\mathrm{tg} /+}$ mice that came from breeding between transgenic Dlx5/6-CIE mice and $\mathrm{Racl}^{+/-}$mice. The Dlx5/6-CIE mice were also PCR genotyped for Cre as mentioned above. Rac1 ${ }^{\text {flox/flox }}$ and $\mathrm{Rac1}{ }^{+/-}$mice were obtained from Dr. David Williams (Cincinnati Children's Hospital Medical Center). Foxg $1^{\text {Cre/+ }}$ mice were obtained from Dr. Susan McConnell (Stanford University, Stanford, CA). Dlx5/6-CIE mice were generated as reported previously (Stenman et al., 2003).

Magnetic resonance imaging of embryos. Embryonic day 18.5 (E18.5) embryos were decapitated and fixed in $4 \%$ paraformaldehyde and stored in saline before the magnetic resonance imaging (MRI) analysis. MR data were acquired using a 7T Bruker (Silberstreifen, Germany) BioSpec system with $38.8 \mathrm{~g} / \mathrm{cm}$ gradients and a $12 \mathrm{~cm}$ bore. A custom-built transmit/ receive solenoid coil with a $1.5 \mathrm{~cm}$ inner diameter oriented perpendicular to the main bore of the magnet was used for data acquisition. A threedimensional (3D) RARE sequence (Hennig et al., 1986) with an echo time of $12 \mathrm{~ms}$, an effective echo time of $96.4 \mathrm{~ms}$, repetition time of 1500 ms, two averages, a matrix of $256 \times 128 \times 144$, and a field of view of $14.4 \times 7.2 \times 8 \mathrm{~mm}$ was used to acquire isotropic axial images. Images were reconstructed in three dimensions using the Cincinnati Children's Hospital Image Processing Software.

Primary cortical neuron culture. The cortices of individual E15.5 embryos were dissected out and digested in the papain/HBSS solution (2 $\mathrm{mg} / \mathrm{ml}$ ) for $20 \mathrm{~min}$ before mechanical dissociation. The cells were suspended with the plating medium (10\% fetal bovine serum in highglucose DMEM) and plated in 24-well culture dishes. The medium was changed to the culture medium (10\% horse serum in DMEM) $2 \mathrm{~h}$ later. The body tissue of embryos was collected for genotyping before the brain dissection. The culture was fixed in $3.7 \%$ formaldehyde at 2 or $4 \mathrm{~d}$ after culture. Immunocytochemistry was subsequently performed following the procedure as described previously (Guo et al., 2003).

Immunohistochemistry. For timed pregnancy, the morning of vaginal plug detection was designated as embryonic day E0.5. All embryos were fixed overnight in $4 \%$ paraformaldehyde, rinsed extensively in PBS, and sunk in $30 \%$ sucrose before sectioning at $10-14 \mu \mathrm{m}$ on a cryostat. Immunostaining was performed as described previously (Toresson and Campell, 2001). Primary antibodies used were as follows: rat anti-L1, 1:200 (Chemicon, Temecula, CA); rabbit anti-Tbr1, 1:5000 (provided by R. Hevner, University of Washington, Seattle, WA); goat anti-Brn1 (1: 1000; Santa Cruz Biotechnology, Santa Cruz, CA); goat anti-calretinin (1:2000; Chemicon); rabbit anti-calbindin (1:2000; provided by P. Emson, The Babraham Institute, Cambridge, UK); rabbit anti-parvalbumin, 1:1000 (provided by P. Emson); mouse anti-Taul (1:400; Chemicon); mouse anti-nestin (1:200; provided by R. McKay, National Institute of Neurological Disorders and Stroke, Bethesda, MD); mouse anti-tubulin III (1:1000; Covance); rat anti-bromodeoxyuridine (BrdU; 1:200; Serotec, Raleigh, NC); rabbit anti-Gad67 (1:2000; Chemicon); rabbit antiEr81 (1:5000; provided by S. Morton and T. Jessell, Columbia University, New York, NY); rabbit anti-GFP conjugated to Alexa Fluor 488 (1:500; Invitrogen, Eugene, OR); rabbit anti-GFAP (1:1000; Dako, Carpinteria, CA); mouse anti-TAG1 (1:100; Developmental Studies Hybridoma Bank, Iowa City, IA). The secondary antibodies used were biotinylated swine anti-rabbit 1:200 (Dako), horse anti-goat (1:200), and goat anti-rat (1:200; Vector Laboratories, Burlingame, CA) antibodies; Alexa 594 goat anti-rat (1:1000); Alexa 594 goat anti-rabbit (1:1000); Alexa 594 goat anti-mouse (1:2000); Alexa 488 goat anti-rabbit (1:1500); Alexa 488 goat anti-chicken (1:1000; Invitrogen); cyanine 3-conjugated donkey anti-goat (1:200; Jackson ImmunoResearch). For biotinylated antibodies, ABC kit (Vector Laboratories) was used to visualize the reaction product using diaminobenzidine (Sigma, St. Louis, MO) as the final chromogen.

Western blot. Forebrain tissues and cultured cortical neurons were lysed and immunoblotted with mouse anti-Racl antibody (1:1000; BD Biosciences, San Jose, CA); mouse anti-Cdc42 antibody (1:250; BD Biosciences); rabbit anti-Rac3 antibody (1:100; provided by Dr. A. Cox, University of North Carolina, Chapel Hill); mouse anti-phospho-focal adhesion kinase (FAK) antibody (1:1000; BD Biosciences); rabbit antiphospho-LIMK antibody (Cell Signaling Technology, Beverly, MA); rabbit anti-phospho-MLCK (Cell Signaling Technology); or mouse antiactin antibody (1:5000; BD Biosciences).

In vivo migration assay. From timed mating, pregnant females were injected intraperitoneally at the appropriate embryonic stages with 0.1 $\mathrm{mg} / \mathrm{g}$ BrdU in PBS. Embryos were collected at appropriate stages, and cryosections were cut. Antigen exposure was achieved by $4 \mathrm{~N} \mathrm{HCl}$ treatment. BrdU-positive cells were counted and plotted as a function of distance from the SVZ.

In situ hybridization. In situ hybridization was performed using digoxigenin-labeled cRNA probes as described previously (Toresson et al., 1999). The probe for Lhx6.1 was described previously (Kimura et al., 1999).

Dye-tracing experiment. Corticothalamic tract tracing experiment was performed using fluorescent carbocyanine dye [1,1'-dioctadecyl3,3,3',3'-tetramethyl-indocarbocyanine (DiI; Invitrogen) following a previous publication (Molnar et al., 1998). Briefly, the DiI crystal was embedded into the cortex of E18.5 mouse embryos, which were kept in $4 \%$ paraformaldehyde for 2 weeks at room temperature, lightproof, before the brain tissues were sectioned coronally with vibratome and examined under fluorescence microscope.

\section{Results}

\section{Conditional gene targeting of Rac1 by Foxg1-Cre mice}

To better define the biological functions of Racl GTPase in neurodevelopment, we crossed Foxg1-Cre mice with a line of mice carrying a floxed Rac1 allele (Gu et al., 2003). In Foxg1-Cre (Foxg1 ${ }^{\mathrm{Cre} /+}$ ) mice, which have Cre knocked in at the Foxg1 locus, the expression of Cre recombinase starts in the anterior neural 


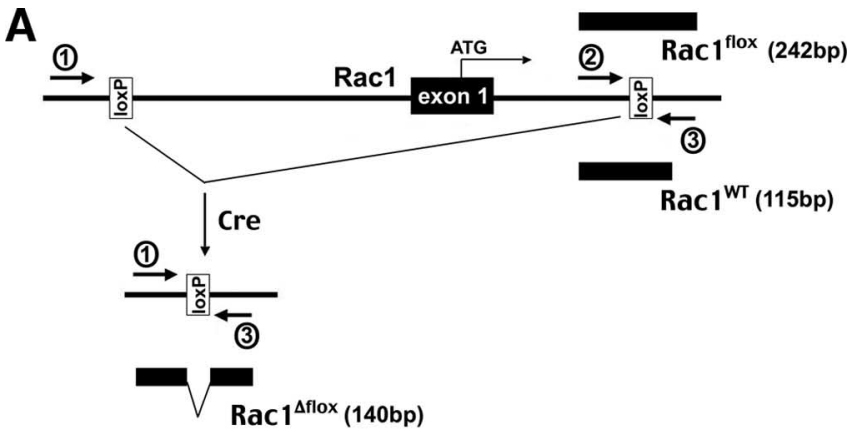

B A: Rac1 $1^{+/ \text {flox }}$
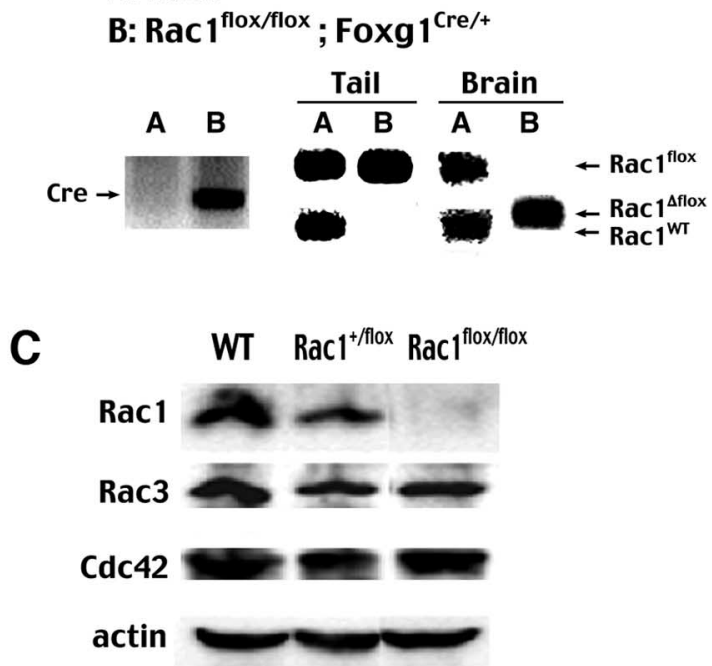

Figure 1. Generation of Foxg1-Cre-driven, forebrain-specific Rac1 conditional knock-out mice. $\boldsymbol{A}$, Schematic representations of the floxed Rac 1 locus before and after the Cre-mediated recombination. Also indicated are the PCR products of wild-type ( $\operatorname{RaC} 1^{\text {WT }}$ ), floxed ( $\operatorname{Rac} 1^{\text {flox }}$ ), and recombined-floxed ( $\operatorname{Rac} 1^{\Delta \text { flox }}$ ) alleles of Rac1. B, Comparison of PCR genotyping analysis using genomic DNA collected from the tail or the forebrain of embryos of different genotypes. Note that the presence of Foxg $1^{\mathrm{Cre} /+}$ transgene converts Rac $1^{\text {flox }}$ into the Rac ${ }^{\Delta \text { flox }}$ allele in genomic DNA in the forebrain but not the tail. C, Immunoblot analysis of Rac1, Rac3, and Cdc42

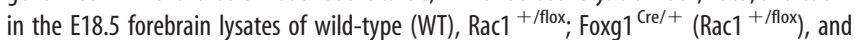
$\operatorname{RaC1}{ }^{\text {flox/flox; }}$ Foxg1 ${ }^{\text {Cre/+ }}$ (Rac1 ${ }^{\text {flox/flox }}$ ) embryos. Actin was used as a loading control. This assay shows that Rac 1 is specifically deleted in the Rac $1^{\text {flox/flox; }}$; Foxg $1^{\text {Cre/+ }}$ embryo without changing the protein levels of Rac3 and Cdc42.

ridge at E8.5 and expands predominantly to the telencephalon and several other brain regions, including the anterior optic vesicle, the isthmus, and the otic vesicle (Hebert and McConnell, 2000). This approach allows us to avoid early (E9.5) embryonic lethality resulting from the germline Rac1-null mutation (Sugihara et al., 1998) and to achieve regional deletion of Racl in the forebrain neuroepithelial progenitors. By breeding Foxg1-Cre and $\mathrm{Racl}{ }^{\text {flox/flox }}$ mice, we obtained embryos of the Rac1 ${ }^{\text {flox/flox; }}$; Foxg $1^{\mathrm{Cre} /+}$ genotype (Fig. $1 \mathrm{~A}$ ). PCR analysis revealed an effective replacement of the floxed Racl allele by the recombined-floxed ( $\Delta$ flox) allele in the brain, but not the tail, of E18.5 Rac1 ${ }^{\text {flox/flox; }}$ Foxg $1^{\text {Cre/t+ }}$ embryos (Fig. $1 B$ ). In these embryos (hereafter referred to as Rac1/Foxg1-Cre embryos), immunoblot analysis indicated the removal of Rac1 protein in the E18.5 forebrain (Fig. 1C). Importantly, the protein levels of the closely related Rac3 and Cdc42 were similar between Rac1/Foxg1-Cre and $\mathrm{Racl}^{+/ \text {flox }}$ embryos (hereafter referred to as control embryos) (Fig. 1C). Interestingly, although the Rac1/Foxg1-Cre embryos were present in a Mendelian ratio from E12.5 to E18.5
( $n=158$ genotyped embryos), there were no viable newborn Rac1/Foxg1-Cre pups $(n>300)$ (supplemental Table 1, available at www.jneurosci.org as supplemental material). This result suggests that Racl has an essential role for the survival of near-term embryos.

\section{Rac1 deficiency causes corpus callosal and commissural axons defects}

We first used Nissl stain to examine potential brain abnormality caused by Racl deficiency in control and Rac1/Foxg1-Cre embryos. Nissl stain revealed that the cortex and the striatum were smaller, and the ventricles were consistently enlarged in E16.5 and E18.5 Rac1/Foxg1-Cre embryos $(n>10)$ (Fig. $2 A, B)$. Moreover, the cerebral cortex of E18.5 Rac1/Foxg1-Cre embryos had disorganized lamination lacking a distinct subplate layer (Fig. $2 \mathrm{~A}$, SP). Nissl stain also suggested that Rac1/Foxg1-Cre embryos lack the anterior commissure (AC), which bilaterally connects the olfactory bulb and the temporal cortex, and have enlarged fornix, which carries the hippocampal efferent fibers to the hypothalamus and the septal area (Fig. 2 B). To confirm this phenotype, we performed immunohistochemical detection of the L1 celladhesion molecule that preferentially labels the thalamocortical, corticofugal, and commissural axons (Fukuda et al., 1997; Brouns et al., 2001). The L1 immunostaining confirmed the absence of $\mathrm{AC}$ and the enlargement of the fornix fiber in Rac1/ Foxg1-Cre embryos (Fig. 2C,D). There was also a reduction of coronal radiata fibers in the internal capsule (IC) containing the thalamocortical and corticothalamic axons in Rac1/Foxg1-Cre embryos (Fig. 2D). Finally, although the corpus callosal (CC) and hippocampal commissural (HC) axons were formed and projected medially in the Rac1/Foxg1-Cre embryos, they did not cross the midline (Fig. $2 E-H$ ).

To further examine the major axon tract defects caused by Racl deficiency, we used T2-weighted MRI and 3D reconstruction to examine E14.5 to E18.5 Rac1/Foxg1-Cre and control embryos ( $n=3$ for each). The T2-weighted MRI reveals global brain morphology and major axonal bundles, including the AC, the $\mathrm{HC}$, the CC, and the fornix (F). Moreover, the $3 \mathrm{D}$ reconstruction allows us to examine these axon tracts in different axial planes and to trace their trajectory at sequential levels. This analysis confirmed the absence of AC in E18.5 Rac1/Foxg1-Cre embryos (compare the transverse view in Fig. $3 A, B$ with the coronal view in Fig. 2 E, $F$ and the sagittal view in Fig. $3 I, J)$. The CC fibers were formed in Rac1/Foxg1-Cre embryos, but they did not cross the midline (Fig. 3, compare $C, D ; E, F ; G, H$ ). The midline-crossing defects of commissural axons were best illustrated in the sagittal view near the center, where the fornix and the $\mathrm{AC}, \mathrm{CC}$, and $\mathrm{HC}$ bundles were clearly identified in the control embryos (Fig. 3I). In contrast, the Rac1/Foxg1-Cre embryos displayed only a prominent fornix bundle near the midline (Fig. 3J). Finally, the Rac1mutant embryos had reduced and uncrossed HC fibers but a thicker fornix bundle projecting to the septal area, strongly suggesting rerouting of the hippocampal efferent fibers (Fig. 3, compare $F, H)$.

Abnormal formation and projection of midline commissural tracts, similar to those observed in the Rac1/Foxg1-Cre embryos, have been reported in mice lacking netrin (Serafini et al., 1996), the receptor of netrin/deleted in colorectal cancer (DCC) (Fazeli et al., 1997), or specific midline glial populations (Richards et al., 2004). However, immunocytochemical detection of GFAP showed no obvious difference of midline glial populations between Rac1/Foxg1-Cre and control embryos from E14.5 to E16.5 ( $n>2$ for each age) (supplemental Fig. 1, available at www.jneu- 


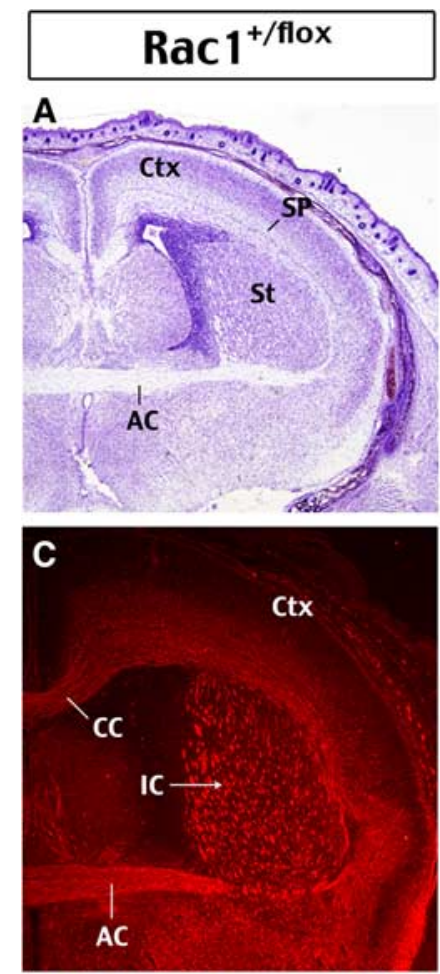

\section{Rac1 $^{\text {flox/flox}} ;$ Foxg $1^{\text {Cre/+ }}$}
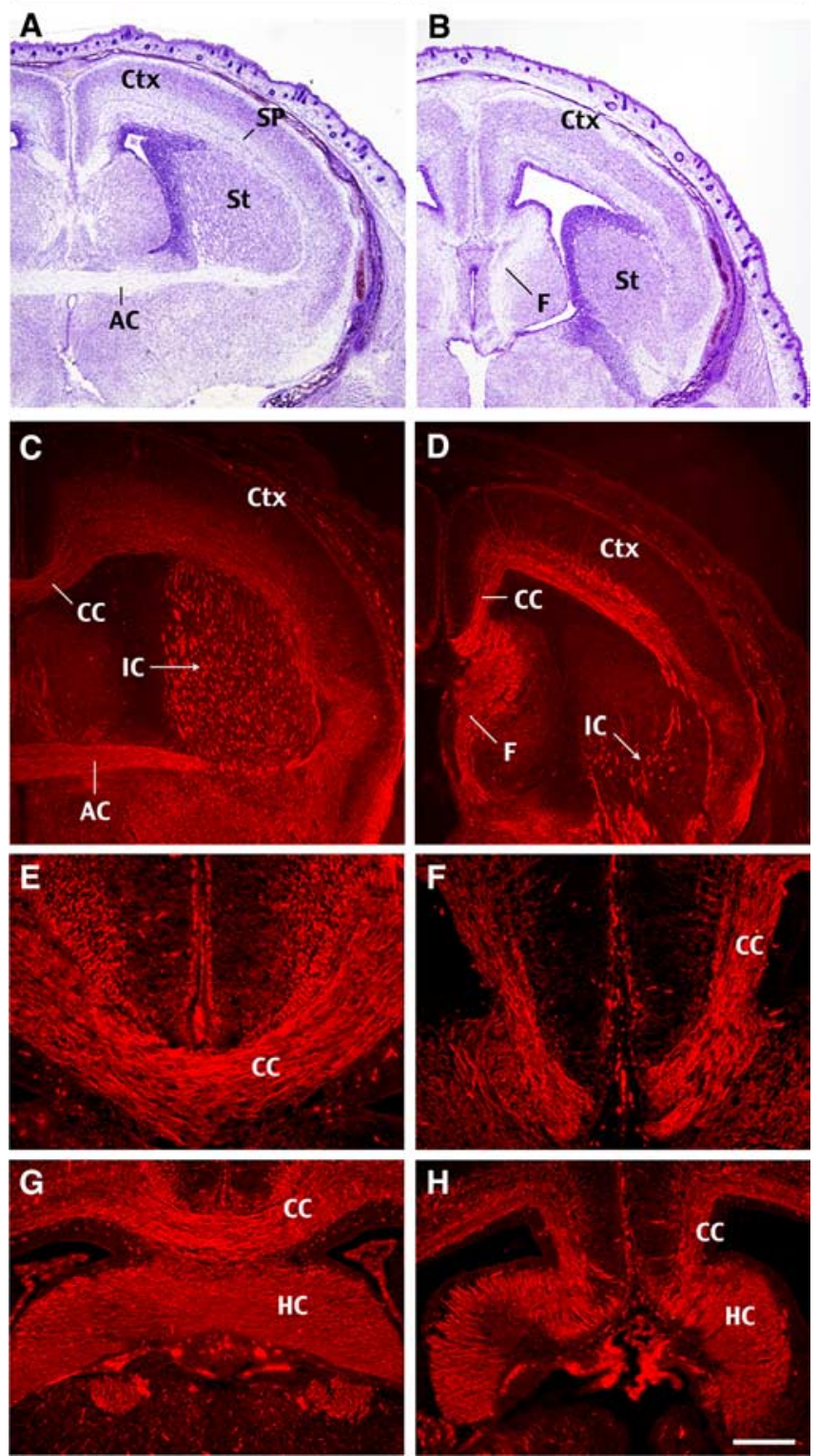

Figure 2. Commissural tract defects in the Rac1-mutant (Rac1 $1^{\text {flox/flox }}$; Foxg1 $\left.{ }^{\mathrm{Cre} /+}\right)$ embryos. $\boldsymbol{A}, \boldsymbol{B}$, Nissl stain shows the abnormalities of E18.5 Rac1-mutant embryo including enlarged ventricles, the absence of $A C$, irregular cortical lamination, and the disappearance of a distinct SP layer, as well as a thicker fornix (F) bundle. $\boldsymbol{C}, \boldsymbol{D}$, Immunostaining for the L1 celladhesion molecule confirms the absence of $A C$ and reduction of the IC fibers in the Rac1-mutant embryos. $\boldsymbol{E}-\boldsymbol{H}$, The $\mathrm{L} 1$ immunostain also confirms midline-crossing defects in the $\mathrm{CC}$ and $\mathrm{HC}$ fibers in the forebrain. Ctx, Cortex. Scale bar (in $\boldsymbol{H}$ ): $\boldsymbol{A}-\boldsymbol{D}, 200 \mu \mathrm{m} ; \boldsymbol{E}-\boldsymbol{H}, 20 \mu \mathrm{m}$.

rosci.org as supplemental material). These results suggest that Racl may be needed in the axonal terminals of commissural fibers to sense environmental cues for crossing the midline.

\section{Racl deficiency causes thalamocortical and corticothalamic axon defects}

The irregular cortical lamination and reduction of coronal radiata fibers in Rac1/Foxg1-Cre embryos prompted us to examine the thalamocortical and the corticothalamic axons using immunocytochemical detection of L1 and transient axonal glycoprotein (TAG1), respectively. E18.5 control embryos showed diffuse L1 immunoreactivity in the cortical plate, suggesting the thalamocortical axons are ascending to their final targets of the layer 4 cortical neurons (Fig. $4 A$ ). In contrast, the L1-positive thalamocortical axons remained as thick bundles in the intermediate zone beneath the cortical plate in Rac1/Foxg1-Cre littermate embryos $(n>6)$ (Fig. $4 B$ ). This result suggests the absence of Racl in the cerebrum leads to a nonpermissive environment, e.g., the absence of a distinct subplate layer (Fig. 3B) (Ghosh et al., 1990), for the formation of thalamocortical connections.

The formation of corticothalamic axons in Rac1/Foxg1-Cre embryos between E14.5 and E16.5 $(n>3)$ was examined by immunostaining of TAG1 (Wolfer et al., 1994; Denaxa et al., 2001). This analysis showed that Racl deficiency does not preclude the formation of corticofugal axons, although their extension toward the subcortical structures appears to be more limited (Fig. 4C,D). To trace the corticofugal projection, crystals of the fluorescent dye DiI were placed in the lateral cortex of E18.5 control and Rac1/Foxg1-Cre embryos ( $n=4$ for each). After 2 weeks of incubation in $4 \%$ paraformaldehyde, the DiI-placed control embryos showed projection of fluorescent fibers toward the thalamus (Fig. 4E). In contrast, Rac1/Foxg1-Cre embryos showed very little extension of the corticofugal axons (Fig. 4E). These results are consistent with the reduction of coronal radiata fibers (Fig. 2D) and suggest that the absence of Rac1 impairs the projection of cortical efferent fibers.

\section{Rac1 is dispensable for neuritogenesis}

Previous studies using a dominant-negative mutant suggested Racl has important functions in neurite formation and extension (Threadgill et al., 1997). However, the phenotypes of Rac1/ Foxg1-Cre embryos suggest that Rac1 directs axon guidance but is not required for neuritogenesis. To examine whether Racl deficiency causes cell-autonomous defects in neurite formation, we cultured the telencephalic neurons from control and Rac1/ Foxg1-Cre embryos for in vitro analysis. PCR analysis indicated the floxed Racl allele was largely converted to a recombinedfloxed ( $\Delta$ floxed) allele in neurons isolated from E14.5 Racl ${ }^{\text {flox/ }}$ flox; Foxg $1^{\text {Cre/+ }}$ embryos (Fig. 5A). Immunoblot analysis also showed a great reduction of the Racl protein level in the mutant neurons (Fig. 5B). The levels of phosphorylated FAK (p-FAK), LIM kinase ( $\mathrm{p}$-LIMK), and MLC kinase ( $\mathrm{p}-\mathrm{MLCK}$ ) were similar between control and Racl-deficient neurons in the culture medium containing 10\% horse serum (Fig. 5B).

Morphological analysis indicated that Rac1-deficient neurons exhibited significant neurite outgrowth at $2 \mathrm{~d}$ in vitro (DIV) culture, similar to control neurons (Fig. $5 D, E$ ). Phalloidin staining showed concentration of actin filaments at the tips of neurite processes in both control and Rac1-deficient neurons (Fig. 5F, G, arrows). By 4 DIV, the control and Rac1-deficient neurons both showed additional extension of the neurite (Fig. $5 \mathrm{H}, \mathrm{I}$ ), and expression of the axonal marker Tau-1 (supplemental Fig. 2, available at www.jneurosci.org as supplemental material). Interestingly, compared with the control neurons, Racl-deficient neurons had an increased number of primary neurites (6.1 vs 3.6, $n=20, p<0.01$ by $t$ test) and secondary branches (4.2 vs 1.45 , $p<0.01$ by $t$ test) (Fig. $5 C$ ). The observed increase of neurite branching in Rac1-deficient neurons is opposite to the consequence caused by overexpression of a dominant-negative Racl mutant (Threadgill et al., 1997). Together, the in vivo and in vitro results strongly suggest that Rac1 GTPase is dispensable for neuritogenesis per se. 

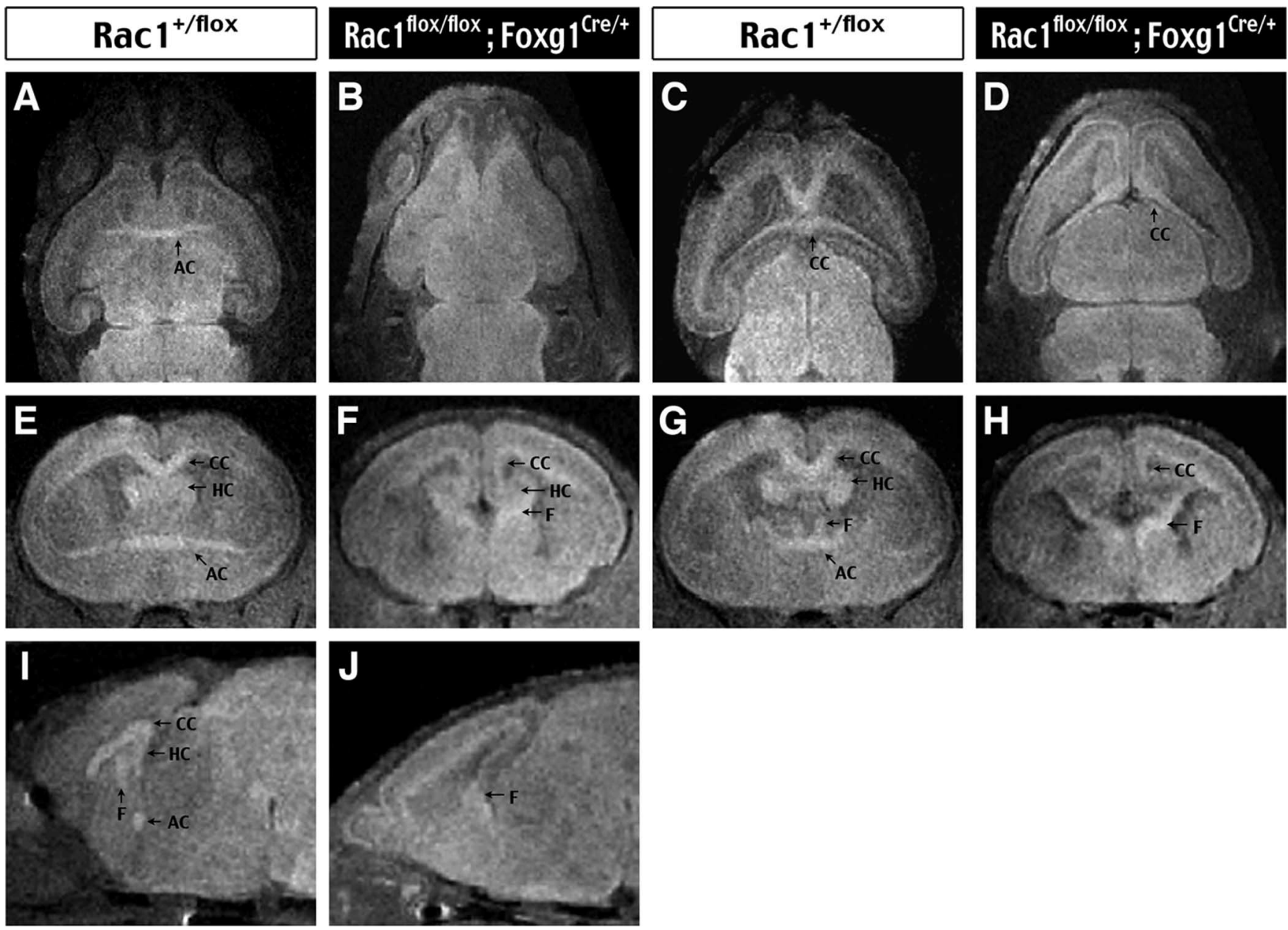

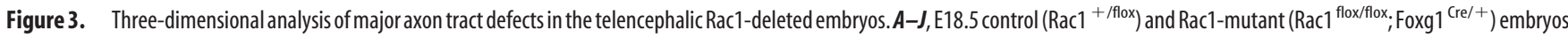
were analyzed by $\mathrm{T}_{2}$-weighted MRI and 3D reconstruction for visualization in the transverse $(\boldsymbol{A}-\boldsymbol{D})$, coronal $(\boldsymbol{E}-\boldsymbol{H})$, and sagittal $(\boldsymbol{I}, \boldsymbol{J})$ axes. Note the absence of $\mathrm{AC}$ and uncrossed $C(\mathrm{C}$ as well as $\mathrm{HC}$ axons in the Rac1-mutant embryos. There was also an increase in thickness of the fornix (F) bundle in the Rac1-mutant embryos. $\boldsymbol{H}$, Rac1-deficient embryos.

Rac1 deletion delays, but does not prevent, radial migration of cortical neurons

A previous study using in utero electroporation to introduce dominant-negative (N17) Rac1 mutant into VZ cells of the cerebral cortex caused $95 \%$ of E14-born neurons, which normally migrate to layers II-IV, to be misplaced in the intermediate zone (Kawauchi et al., 2003). This study suggested that Racl plays a critical role in directing cortical neuronal migration. To test this possibility, the birth-dating analysis was performed in Rac1/Foxg1-Cre embryos and control littermates. In this analysis, BrdU was injected in the pregnant mice at E10.5/E11.5 or E15.5 to label newborn neurons, and the distribution of BrdU-positive incorporated cells in the cerebrum was examined at E17.5 or E18.5, respectively. According to the inside-to-outside sequence of cortical neurogenesis (Angevine and Sidman, 1961), the majority of E10.5/E11.5-born layer 6/subplate (VI/SP) neurons will locate in the intermediate zone, whereas the later-born E15.5 neurons migrate to the upper cortical plate in E17/18 embryos. Conversely, if Rac1 has essential functions in neuronal migration, there should be a reverse distribution of E10.5/E11.5- and E15.5-born neurons in the cerebrum as has been shown in the reeler and p35-null mutants (Caviness and Sidman, 1973; Chae et al., 1997).

This analysis revealed that the majority of E10.5/E11.5born VI/SP neurons were located in the intermediate zone of
E17.5 cerebral cortex in both control and Rac1/Foxg1-Cre embryos (Fig. $6 A, B$ ). Immunostaining of Tbr 1 and calretinin, markers for the deep and superficial layer cortical neurons, respectively, also showed an identical pattern in both control and Rac1/Foxg1-Cre embryos at E18.5 (supplemental Fig. $3 A-D$, available at www.jneurosci.org as supplemental material). The nestin-positive radial glial fibers, which are the scaffold of cortical neuronal migration, also developed properly in Rac1/Foxg1-Cre embryos (supplemental Fig. 3E,F, available at www.jneurosci.org as supplemental material). However, when compared with control embryos, Rac1/Foxg1-Cre embryos displayed a larger percentage of E15.5-born neurons in the bottom quarter ( $41 \%$ vs $18 \% ; p<0.01$ by $t$ test) and a smaller percentage in the top quarter $(18 \%$ vs $38 \% ; p<0.01$ by $t$ test) in the E18.5 developing cerebrum (Fig. 6C-E) (a total of 5640 cells were counted in three embryos of each genotype). Similarly, immunocytochemistry of Brn-1, a marker of neurons destined for the superficial cortical layers, showed that an increased number of positively stained cells remained in the intermediate zone in E18.5 Rac1/Foxg1-Cre embryos, when compared with control littermates (Fig. 6F,G). Together, these results indicate that Racl deficiency is insufficient to avert cortical neuronal migration. However, Racl deficiency may delay the onset or reduce the speed of cortical neuronal migration. 


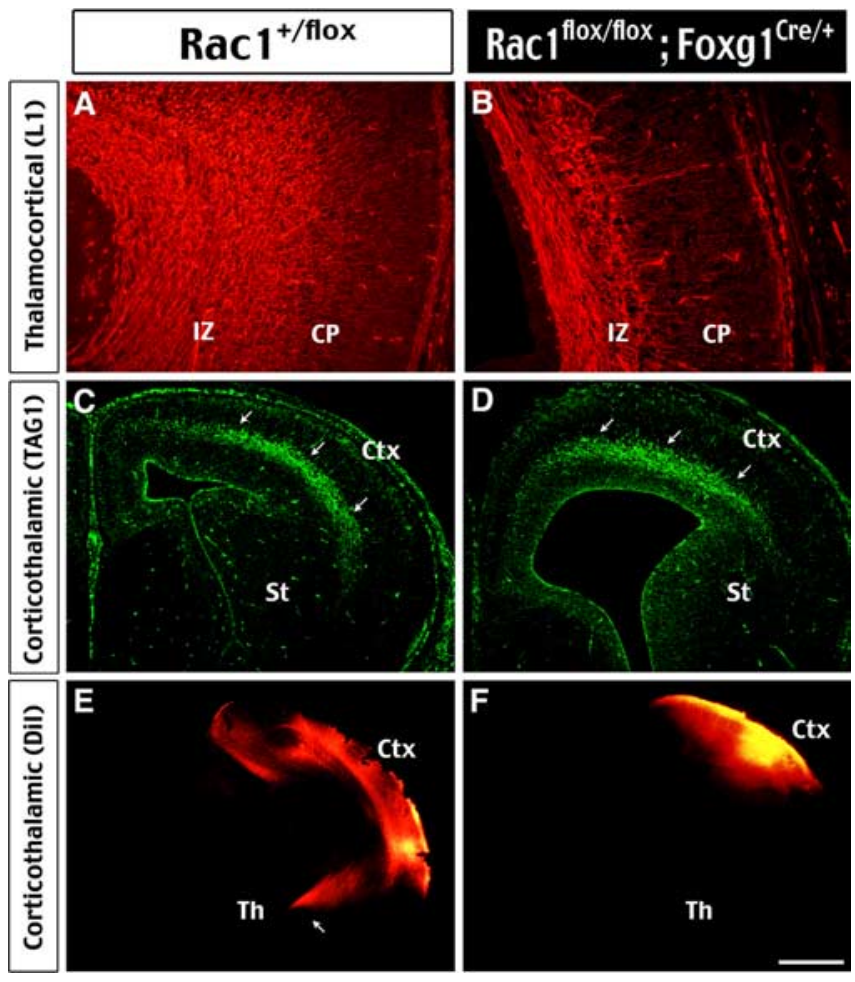

Figure 4. Rac1 deletion causes defects of thalamocortical and corticothalamic connections. $\boldsymbol{A}, \boldsymbol{B}, \mathrm{L}$ 1 immunostaining shows the thalamocortical axons have ascended into the developing cortical plate $(C P)$ in control $\left(\mathrm{RaCl}^{+/ \text {flox }}\right)$ embryos at E18.5, whereas their counterparts in the Rac1-mutant (Rac1 ${ }^{\text {flox/flox; }}$ Foxg $1^{\mathrm{Cre} /+}$ ) embryos are halted in the intermediate zone (IZ). C, D, TGA1 immunostaining shows the formation of corticothalamic axons (arrows) in the base of developing cerebrum of both control and Rac1-mutant embryos at E16.5. St, Striatum. $\boldsymbol{E}-\boldsymbol{H}$, Crystals of Dil placed in the lateral cerebral cortex (Ctx) label the efferent fibers into the thalamus (Th) in E18.5 control embryos ( $\boldsymbol{E}$ ) but not in Rac1-mutant embryos $(\boldsymbol{F})$. Scale bar (in $\boldsymbol{F}$ ): $\boldsymbol{A}, \boldsymbol{B}, 40$ $\mu \mathrm{m} ; \boldsymbol{C}, \boldsymbol{D}, 200 \mu \mathrm{m} ; \boldsymbol{E}, \boldsymbol{F}, 400 \mu \mathrm{m}$.

\section{Racl deletion in the $\mathrm{VZ}$ averts tangential migration of ventral} telencephalic neurons

In addition to radial migration of cortical projection neurons, recent studies have uncovered tangential migration by neurons born in the ventral telencephalon during embryogenesis (Corbin et al., 2001; Marin and Rubenstein, 2003; Metin et al., 2006). There are two major routes of the long-distance tangential migration: the lateral ganglionic eminence (LGE)-derived neurons migrate anteriorly, giving rise to olfactory interneurons (Wichterle et al., 2001); the medial ganglionic eminence (MGE)derived cells migrate to the cerebral cortex and become GABAergic interneurons (Anderson et al., 1997). Interestingly, all Rac1/ Foxg1-Cre embryos have particularly smaller olfactory bulbs compared with control embryos (Fig. $7 A, B$ ). This conspicuous anomaly suggests that Racl deficiency may affect the tangential migration of LGE-derived olfactory neurons. To test this possibility, we examined the olfactory bulbs of E18.5 control and Rac1/ Foxg1-Cre embryos by Nissl stain and anti-GAD67 immunostaining. This analysis showed the absence of GABAergic neurons in the granule cell layer and in the glomerular layer in Racl/ Foxg1-Cre embryos (rostral sections shown in Fig. 7C,D; caudal sections of olfactory bulbs shown in supplemental Fig. $4 A, B$, available at www.jneurosci.org as supplemental material). The number of Er81-positive interneurons was also reduced in the olfactory bulb of Rac1/Foxg1-Cre embryos (supplemental Fig. $4 C, D$, available at www.jneurosci.org as supplemental material). In contrast, GAD67-positive cells were found in the ventral tel- encephalon of Rac1/Foxg1-Cre embryos (Fig. 7 E,F), suggesting that Racl deficiency interferes with tangential migration rather than the formation of LGE-derived olfactory interneurons.

Furthermore, almost no GAD67-positive cells were found in the cerebral cortex of E18.5 Rac1/Foxg1-Cre embryos (Fig. $7 \mathrm{~K}, L$ ), suggesting that the migration of MGE-derived cortical interneurons was also affected by Racl deletion. To further test this possibility, we used in situ hybridization of Lhx6.1, a marker for MGE-derived neurons (Kimura et al., 1999; Lavdas et al., 1999), to examine control and Rac1/Foxg1-Cre embryos between E14.5 and E16.5 ( $n=2$ from each age). At E14.5, the Lhx6.1 transcripts were found inside the MGE in both control and Rac1/ Foxg1-Cre embryos, suggesting that the formation of the presumptive cortical interneurons was not precluded by Rac1 deficiency (Fig. 7G,H). By E16.5, the Lhx6.1-postive cells were widely dispersed in the striatum and the developing cortical cerebrum in control embryos (Fig. 7I), consistent with the migratory pattern of MGE-derived neurons (Lavdas et al., 1999). In contrast, the Lhx6.1-postive cells remained confined in the mantle region of the MGE in E16.5 Rac1/Foxg1-Cre embryos (Fig. 7J, arrow). Together, these results indicate that the Foxg1-Cre-directed deletion of Racl in the VZ severely disrupts the tangential migration of both LGE- and MGE-derived olfactory and cortical interneurons.

\section{Rac1 deletion in the SVZ does not affect the migration of ventral telencephalic neurons}

The contrasting severity of migratory defects of dorsal (Fig. 6) and ventral telencephalic neurons (Fig. 7) in Rac1/Foxg1-Cre embryos may indicate that Rac1 is differentially required for cellular motility between these two populations of neurons. Alternatively, Racl may have a unique role during progenitor differentiation in the ventral telencephalon to establish the competency of migration in nascent neurons. Similar examples of ventral telencephalic progenitor-specific requirement of signaling molecules for neuronal differentiation have been demonstrated previously (Mason et al., 2005; Xu et al., 2005).

To distinguish between these two possibilities, we used another line of Cre-driver, Dlx5/6-CIE mice (Stenman et al., 2003), to delete Rac1 in cells emerging from the VZ in the ventral telencephalon. In Dlx5/6-CIE mice, the expression of EGFP (a surrogate marker of Cre recombinase) starts as early as E10.5 in the SVZ of the future LGE and MGE, which contains SVZ progenitors and nascent postmitotic neurons (Fig. 8A). At E14.5, the expression of EGFP can be detected in the entire striatum except the VZ (Fig. 8 B). After the cross of Rac1 ${ }^{+/-}$; Dlx5/6-CIE ${ }^{\mathrm{tg} /+}$ and $\mathrm{Racl}^{\text {flox/flox }}$ mice, pups of the Rac1 ${ }^{-/ \text {flox }}$; Dlx $5 / 6-\mathrm{CIE}^{\mathrm{tg} /+}$ genotype were derived in an expected Mendelian ratio (supplemental Table 2, available at www.jneurosci.org as supplemental material). PCR analysis showed near-complete recombination at the floxed-Rac1 locus in the striatum of E18.5 Rac1 ${ }^{-/ \text {flox }}$; Dlx5/6$\mathrm{CIE}^{\mathrm{tg} /+}$ genotype (hereafter referred to as Rac1/Dlx5/6-CIE) (Fig. $8 C$ ). Interestingly, no discernible abnormality was found in the brains of E18.5 Rac1/Dlx5/6-CIE embryos by Nissl stain (Fig. $8 D, E)$. Immunostaining by anti-GAD67 antibody also revealed proper formation of the granule cell layer and the glomerular layer of the olfactory bulb in these embryos (Fig. $8 F, G$ ). Moreover, numerous ventral telencephalic-derived EGFP-positive cells were found in the cerebral cortex of E18.5 control and Rac1/ Dlx5/6-CIE embryos (Fig. $8 H, I$ ). In addition, at postnatal day 12 (P12), control and Rac1/Dlx5/6-CIE mice showed a similar number and an identical distribution pattern of parvalbuminand calbindin-positive interneurons in the cerebrum (Fig. 
$8 L, M)$. Together, these results suggest that Racl is not essential for the motility per se during tangential migration of LGEand MGE-derived interneurons.

\section{Discussion}

Overexpression of dominant-negative or constitutive-active mutants of Rho-GTPases, including Rac1, has been the predominant strategy for deducing their functions. Although this approach has revealed many important functions of Rac1 (for review, see Govek et al., 2005), there is also concern of the specificity of the phenotypes induced by the mutants. A good example is in Drosophila Rac (Drac1 and Drac2): although overexpression of dominant-negative Dracl prevents axonal outgrowth, subsequent genetic studies showed that progressive loss of Drac1, Drac2, and the related Mtl activity leads first to defects in axonal branching, then guidance, and finally axonal outgrowth (Luo et al., 1994; Ng et al., 2002). These subtle but important functions of Rac GTPases would have been masked without specific gene mutation studies. Hence, it is necessary to compare the phenotypes of overexpression of dominant mutants with those of targeted disruption of individual Rho GTPase to deduce its biological functions (Wang and Zheng, 2007). In the present study, we have applied a conditional genetargeting strategy to examine the roles of Racl during mouse forebrain development. To our knowledge, this is the first directed gene-deletion study of Racl in the mammalian nervous system.

\section{Role of Racl in axon projection versus neuritogenesis}

Previous studies using dominant mutants have implicated Rac1 GTPase in neurite formation and growth cone functions (Govek et al., 2005). It is generally agreed that $\mathrm{Racl}$ and Cdc42 promote, whereas RhoA inhibits, neurite outgrowth (Da Silva and Dotti, 2002). In addition, a signaling cascade from Cdc42 to PAR-6/ PAR-3/Sif and Tiam1-like exchange factor (STEF) to Rac was implicated in establishing the axon/dendrite polarity in neurons (Nishimura et al., 2005). However, our results in Foxg1-Cremediated deletion of Racl show that Racl-null neurons are mostly unaffected in axon formation per se (Figs. 3-5). These results indicate that Rac1 is not essential for neuritogenesis, in contrast with previous studies using dominant-negative Rac1 mutant. One likely explanation of this discrepancy is that overexpression of dominant-negative mutant may disrupt the activities of other Rac1-related GTPases, such as Rac3 or Cdc42, which also contribute to neuritogenesis.

Although Rac1 is dispensable for neuritogenesis, our results indicate that Rac1 has a critical role in the projection of commissural and corticothalamic axons (Figs. 2-4). In the absence of Rac1, the corpus callosal and hippocampal commissural axons projected medially but failed to cross the midline despite the formation of specific midline glial cell populations that are important factors for midline crossing (Serafini et al., 1996; Richards et al., 2004). Interestingly, similar defects of commissural tracts were also seen in mice lacking the netrin receptor DCC
B

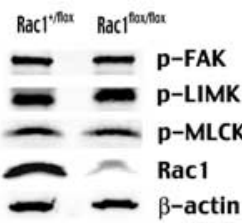

$p<0.0$

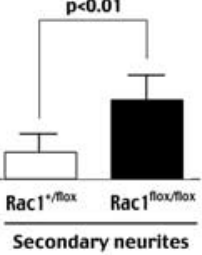

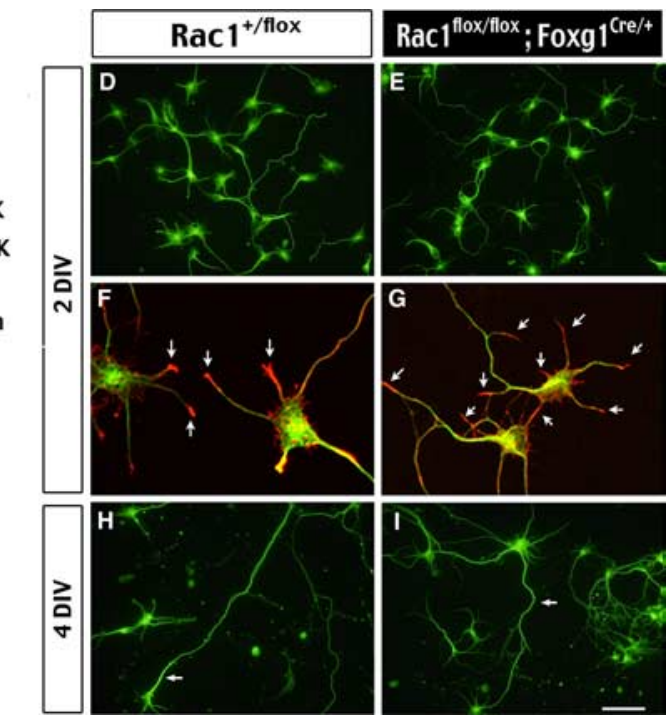

Figure 5. Neurite formation in the absence of Rac1 GTPase. $\boldsymbol{A}, \mathrm{PCR}$ analysis shows the floxed Rac1 allele is near-completely replaced by the recombined-floxed allele of $\operatorname{Rac} 1\left(\operatorname{Rac} 1^{\Delta \text { flox }}\right.$ ) in the telencephalic neurons cultured from E14.5 $\operatorname{Rac} 1^{\text {flox/flox }}$; ( ) embryos. WT, Wild type. $\boldsymbol{B}$, Immunoblots show great reduction of the Rac1 protein level, but not those of phospho, the neuronal cell lysates. Shown are representatives of three sets of experiments. $\boldsymbol{C}$ neurons. Rac1-mutant neurons have a significantly increased complexity of the neurite formation ( $p<0.01$ by $t$ test). $\boldsymbol{D}, \boldsymbol{E}$, 列 $\beta$-tubulin III of Rac1 ${ }^{+}$and Rac1-mutant neurons at 2 DIV. F, G, Double labeling of anti- $\beta$-tubulin II (red) shows that F-actin is also concentrated in the growth cones of control and Rac1-mutant neurons. $\boldsymbol{H}$ I, Immunostaining of $\beta$-tubulin III of control and Rac1-mutant neurons at 4 DIV. Note the extension of axons (arrow) in neurons

(Fazeli et al., 1997). Furthermore, genetic studies suggested that CED-10/Rac is one of the downstream effectors of the UNC-40/ DCC signaling in Caenorhabditis elegans (Gitai et al., 2003). Collectively, our results and the previous studies indicate that mammalian Racl may relay the signaling cascade from DCC in the growth cone of callosal and commissural axons as suggested recently (Shekarabi et al., 2005). In addition, Rac1 may have a broader function in axon guidance because the deletion of Rac1 also disrupts the formation of proper corticothalamic connections (Fig. 5). Together, we propose that Racl has important functions in the growth cone for sensing a spectrum of external guidance molecules. Future studies using in vitro cultures of Rac1-null neurons are needed to define the detailed mechanisms.

\section{Differential roles of Racl in tangential versus radial neuronal migration}

Studies using dominant mutants suggest that Rac1 and/or Cdc42 modulate the assembly of microtubules during cell migration (Watanabe et al., 2004; Raftopoulou and Hall, 2004). Consistent with this hypothesis, in utero electroporation of dominantnegative Rac1 or its upstream regulator STEF/Tiam1 into VZ progenitors in mouse embryos almost completely inhibited the radial migration of cortical neurons (Kawauchi et al., 2003). It was shown that $95 \%$ of layer 2-4 neurons were halted in the intermediate zone of mutant Rac1-transfected brains. However, compared with this severe consequence after mutant Rac1 transfection, the migration defect in cortical neurons caused by deletion of Rac1 with Foxg1-Cre mice is milder. Our results indicate that the inside-to-outside sequence of neurogenesis and migration is preserved in the Racl-deficient cerebrum (Fig. 6). The different severity of migration defects between these two approaches suggests that overexpression of dominant-negative mutants in previous studies may have altered the activity of other 

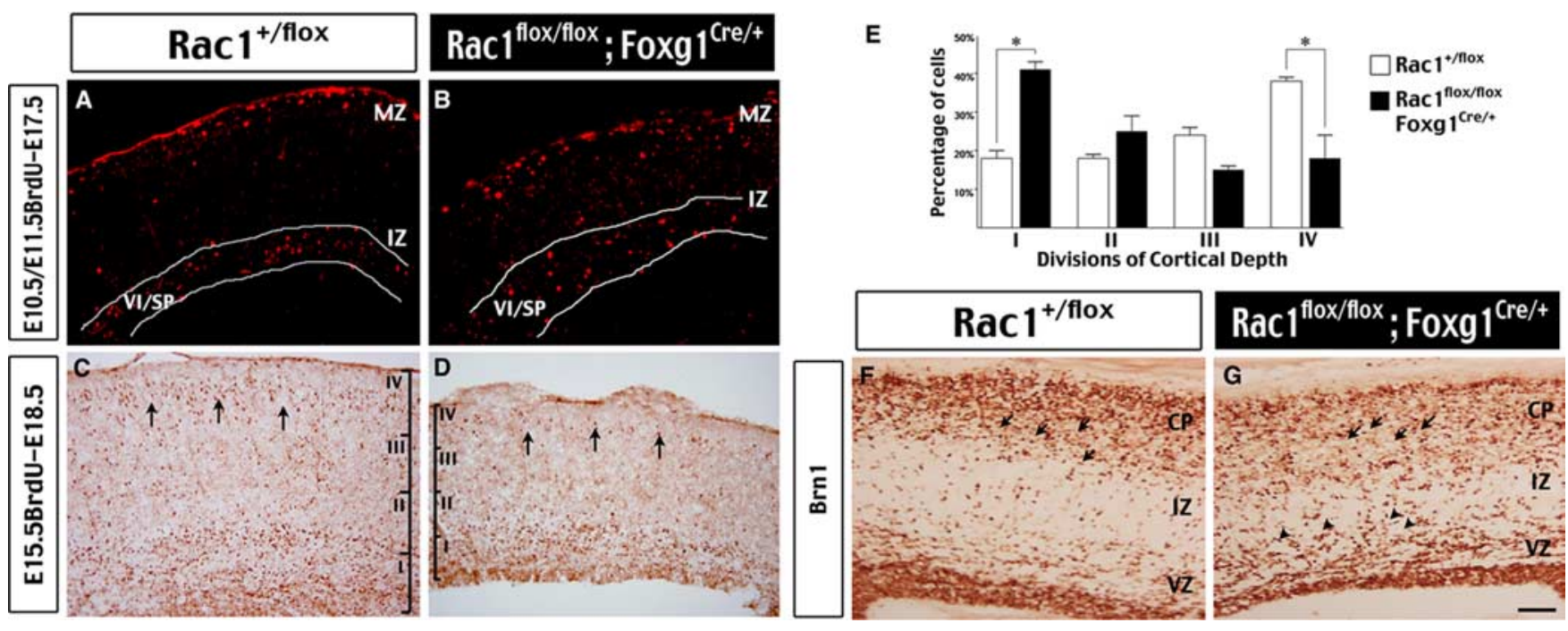

Figure 6. Preserved radial migration of cortical neurons in the absence of Rac1 GTPase. $\boldsymbol{A}, \boldsymbol{B}$, Birth-dating analysis with BrdU injected at E10.5 and E11.5 and the embryos examined at E17.5. Similar to control embryos, the majority of BrdU-positive, VI/SP neurons (highlighted by white lines) are located in the intermediate zone (IZ) of both control (Rac1 + /flox) and Rac1-mutant (Rac1 flox/flox; Foxg ${ }^{\text {Cre/+ }}$ ) embryos. MZ, Marginal zone. C-E, Birth-dating analysis with BrdU injected at E15.5 and the embryos examination at E18.5. The number of BrdU-positive cells in four equal sectors (I-IV) of the cortex were quantified for comparison (3 embryos for each genotype and a total of 5640 cells were counted to derive the histogram). The percentage of BrdU-positive cells is significantly increased in the bottom quarter (I) and decreased in the top quarter (IV) of developing cerebral cortex in Rac1-mutatnt embryos ( ${ }^{*} p<0.01$ by $t$ test). $\boldsymbol{F}, \boldsymbol{G}$, Immunostaining of Brn1, a marker of neurons destined for the upper cortical layer, shows more positively labeled cells in the IZ in E18.5 Rac1-mutant embryos compared with age-matched control embryos. This pattern is consistent with delayed migration of cortical neurons. Scale bar (in G): $A-D, 200 \mu \mathrm{m} ; \boldsymbol{F}, \mathbf{G}, 40 \mu \mathrm{m}$.

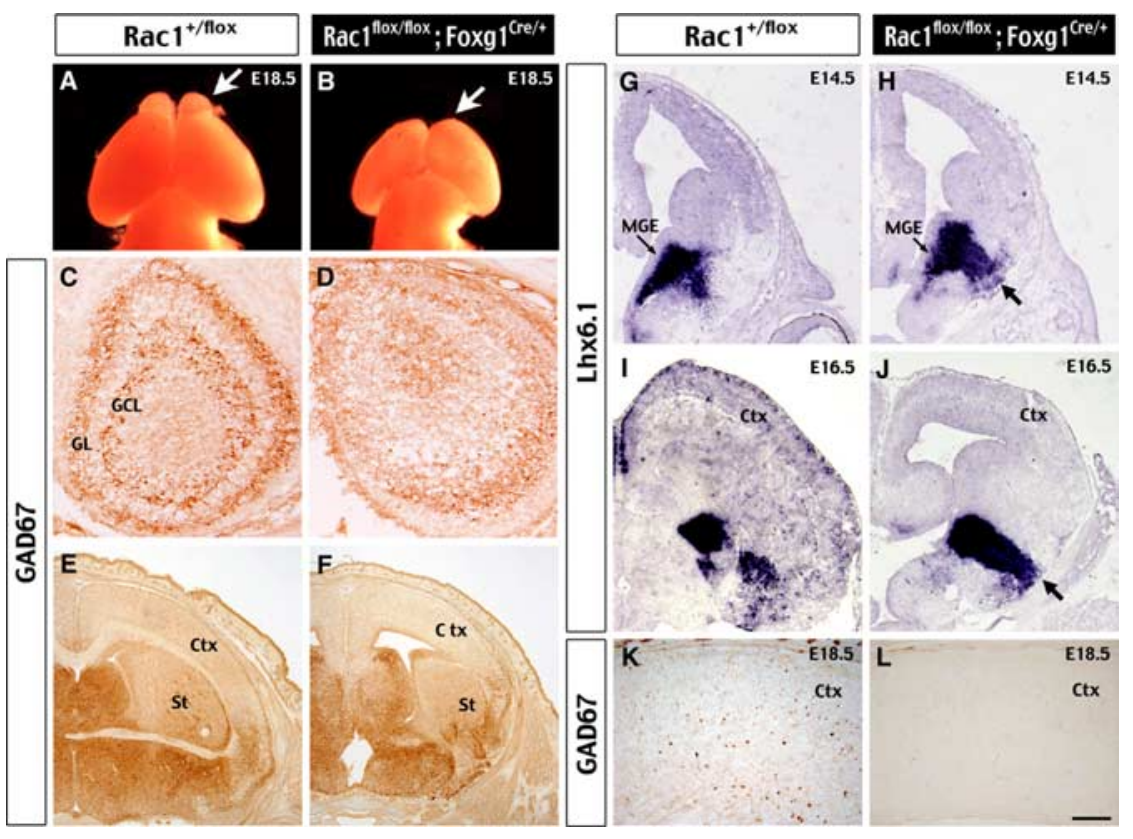

Figure 7. Abnormal distribution of ventral telencephalon-derived interneurons in Rac1 ${ }^{\text {flox/flox }} ; \mathrm{Foxg}_{1}{ }^{\mathrm{Cr} /+}{ }^{\mathrm{emb} b r y 0 s} . \boldsymbol{A}, \boldsymbol{B}, \mathrm{The}$ olfactory bulbs (arrow) were disproportionately small in E16.5 to E18.5 Rac1 ${ }^{\text {flox/flox; }}$ Foxg $1^{\mathrm{Cre} /+}$ embryos compared with littermates. $C, D$, Immunohistochemistry for GAD67 shows the LGE-derived GABAergic interneurons are markedly decreased in the olfactory bulb of Rac1-mutant embryos. GL, Glomerular layer; GCL, granule cell layer. $\boldsymbol{E}, \boldsymbol{F}$, In contrast, GAD67-positive cells were detected in the basal forebrain of both control and Rac1-mutant embryos. G-J, In situ hybridization of Lhx6.1 shows equal formation of GABAergic interneurons in the MGE (small arrow) of control and Rac1-mutant embryos at E14.5. However, Lhx6.1-expressing cells are halted in the mantle region of MGE (large arrow) in the Rac1-mutant embryos at E16.5 (J), when compared with control littermate embryos $(\boldsymbol{I}) . \boldsymbol{K}, \boldsymbol{L}$, Immunostaining shows many GAD67-positive cells, a marker for cortical interneurons, in the cerebral cortex of E18.5 control embryos $(\boldsymbol{K})$, but not in Rac1-mutant embryos (L). Scale bar (in $L): C, D, 100 \mu \mathrm{m} ; \boldsymbol{E}-J, 400 \mu \mathrm{m} ; \boldsymbol{K}, \boldsymbol{L}, 40 \mu \mathrm{m}$.

Rho-GTPases that are collectively needed for the radial migration of cortical neurons.

In contrast to the mild defect of radial neuronal migration, there is a severe reduction of the olfactory and cortical interneu- rons in the Foxg1-Cre-directed Racl mutant embryos (Fig. 7), suggesting that Rac1 has an essential role in the tangential migration of LGE- and MGE-derived neurons. In situ hybridization of Lhx6.1 reveals that the MGE-derived neurons are formed in the Rac1-null embryos, but they are halted in the mantle region of ventral telencephalon unable to engage in the long-distance tangential migration (Anderson et al., 1997; Corbin et al., 2001; Marin and Rubenstein, 2003). Although the abnormality of TAG1-positive corticofugal axons may contribute to tangential migration defects in Foxg1-Cre-mediated Rac1 mutant embryos (Denaxa et al., 2001), the failure of migration in both olfactory and cortical interneurons suggests cell-autonomous defects in the LGE- and MGE-derived neurons.

Progenitor-specific function of Rac1 for the competency of neuronal migration Cell-autonomous defects in migration, however, may be because of an inability to execute cell movement (motility defect) or improper expression of receptors for the attractive and/or repulsive cues, rendering the neurons unable to respond to environmental cues for migration (competency defect). In addition, previous studies have shown that, before migration, neurons have to enter a proper differentiation state to use the cell movement machinery (Kuhar et al., 1993; Hatten, 1999). Because migration is so intimately linked to the establishment of cell fate, the defects of tangential migration of LGE- and 
MGE-derived interneurons in Rac1/ Foxg1-Cre embryos may indicate progenitor-specific functions of Racl for establishing the competency of migration in subsequent neurons. This is an exciting possibility, although almost nothing is known about the role of Racl GTPase in neural progenitors (Govek et al., 2005).

To test this possibility, we have used a second line of Cre-driver mice, the Dlx5/ 6-Cre-IRES-EGFP mice, to delete Rac1 in the ventral telencephalon (Stenman et al., 2003). An important difference between these two lines of Cre-driver mice is that Foxg1-directed Cre expression occurs in neural progenitors in the VZ (Hebert and McConnell, 2000), whereas the Dlx5/6directed Cre expression starts in cells exiting the VZ and into the SVZ (Fig. $8 A$ ). Hence, the progenitor functions of Racl are preserved in the $\mathrm{VZ}$ progenitors by Dlx5/6-Cre-mediated deletion. We found that, although both lines of mice produced effective deletion of Racl in the striatum, only Foxg1-Cre-mediated deletion of $\mathrm{Rac} 1$ in the VZ progenitors caused defects of tangential migration of LGE- and MGEderived interneurons. Therefore, the failure of tangential migration in Racl/ Foxg1-Cre embryos is not attributable to a primary abnormality of cell motility. Instead, these contrasting outcomes suggest a novel function of Racl during the VZ progenitor differentiation to establish the migratory competency of subsequent ventral telencephalic neurons.

In conclusion, the present study of regional-specific deletion of Rac1 uncovers its functions not widely appreciated in previous studies using dominant mutants. Specifically, our genetic study demonstrates that Rac1 has a critical role in axon guidance and in neural progenitor differentiation.

\section{References}

Anderson SA, Eisenstat DD, Shi L, Rubenstein JL (1997) Interneuron migration from basal forebrain to neocortex: dependence on Dlx genes. Science 278:474-476.

Angevine JB, Sidman RL (1961) Autoradiographic study for cell migration during histogenesis of cerebral cortex in the mouse. Nature 192:766-768.

Aoki K, Nakamura T, Matsuda M (2004) Spatio-temporal regulation of Rac1 and Cdc42 activity during nerve growth factor-induced neurite outgrowth in PC12 cells. J Biol Chem 279:713-719.

Bishop AL, Hall A (2000) Rho GTPases and their effector proteins. Biochem J 348:241-255.

Brouns MR, Matheson SF, Settleman J (2001) p190 RhoGAP is the principal Src substrate in brain and regulates axon outgrowth, guidance and fasciculation. Nat Cell Biol 3:361-367.

Caviness VSJ, Sidman RL (1973) Time of origin of corresponding cell classes in the cerebral cortex of normal and reeler mutant mice: an autoradiographic analysis. J Comp Neurol 148:141-152.

Chae T, Kwon YT, Bronson R, Dikkes P, Li E, Tsai LH (1997) Mice lacking p35, a neuronal specific activator of Cdk5, display cortical lamination defects, seizures, and adult lethality. Neuron 18:29-42.

Corbetta S, Gualdoni S, Albertinazzi C, Paris S, Croci L, Consalez CG, de Curtis I (2005) Generation and characterization of Rac3 knockout mice. Mol Cell Biol 25:5763-5776.
Corbin JG, Nery S, Fishell G (2001) Telencephalic cells take a tangent: nonradial migration in the mammalian forebrain. Nat Neurosci 4[Suppl]:1177-1182.

da Silva JS, Dotti CG (2002) Breaking the neuronal sphere: regulation of the actin cytoskeleton in neuritogenesis. Nat Rev Neurosci 3:694-704.

Denaxa M, Chan CH, Schachner M, Parnavelas JG, Karagogeos D (2001) The adhesion molecule TAG-1 mediates the migration of cortical interneurons from the ganglionic eminence along the corticofugal fiber system. Development 128:4635-4644.

Etienne-Manneville S, Hall A (2002) Rho GTPases in cell biology. Nature 420:629-635.

Fazeli A, Dickinson SL, Hermiston ML, Tighe RV, Steen RG, Small CG, Stoeckli ET, Keino-Masu K, Masu M, Rayburn H, Simons J, Bronson RT, Gordon JI, Tessier-Lavigne M, Weinberg RA (1997) Phenotype of mice lacking functional deleted in colorectal cancer (Dcc) gene. Nature 386:796-804.

Fukuda T, Kawano H, Ohyama K, Li HP, Takeda Y, Oohira A, Kawamura K (1997) Immunohistochemical localization of neurocan and L1 in the formation of thalamocortical pathway of developing rats. J Comp Neurol 382:141-152.

Ghosh A, Antonini A, McConnell SK, Shatz CJ (1990) Requirement for subplate neurons in the formation of thalamocortical connections. Nature 347:179-181.

Gitai Z, Yu TW, Lundquist EA, Tessier-Lavigne M, Bargmann CI (2003) The netrin receptor UNC-40/DCC stimulates axon attraction and outgrowth through enabled and, in parallel, Rac and UNC-115/AbLIM. Neuron 37:53-65.

Govek EE, Newey SE, Van Aelst L (2005) The role of the Rho GTPases in neuronal development. Genes Dev 19:1-49.

Gu Y, Filippi MD, Cancelas JA, Siefring JE, Williams EP, Jasti AC, Harris CE, 
Lee AW, Prabhakar R, Atkinson SJ, Kwiatkowski DJ, Williams DA (2003) Hematopoietic cell regulation by Racl and Rac2 guanosine triphosphatases. Science 302:445-449.

Guo F, Gao Y, Wang L, Zheng Y (2003) p19Arf-p53 tumor suppressor pathway regulates cell motility by suppression of phosphoinositide 3-kinase and Racl GTPase activities. J Biol Chem 278:14414-14419.

Haataja L, Groffen J, Heisterkamp N (1997) Characterization of RAC3, a novel member of the Rho family. J Biol Chem 272:20384-20388.

Hatten ME (1999) Central nervous system neuronal migration. Annu Rev Neurosci 22:511-539.

Hebert JM, McConnell SK (2000) Targeting of cre to the Foxg1 (BF-1) locus mediates loxP recombination in the telencephalon and other developing head structures. Dev Biol 222:296-306.

Hennig J, Nauerth A, Friedburg H (1986) RARE imaging: a fast imaging method for clinical MR. Magn Reson Med 3:823-833.

Jaffe AB, Hall A (2005) RHO GTPASES: Biochemistry and biology. Annu Rev Cell Dev Biol 21:247-269.

Kawauchi T, Chihama K, Nabeshima Y, Hoshino M (2003) The in vivo roles of STEF/Tiam1, Racl and JNK in cortical neuronal migration. EMBO J 22:4190-4201.

Kimura N, Ueno M, Nakashima K, Taga T (1999) A brain region-specific gene product Lhx6.1 interacts with Ldb1 through tandem LIM-domains. J Biochem (Tokyo) 126:180-187.

Kuhar SG, Feng L, Vidan S, Ross ME, Hatten ME, Heintz N (1993) Changing patterns of gene expression define four stages of cerebellar granule neuron differentiation. Development 117:97-104.

Lavdas AA, Grigoriou M, Pachnis V, Parnavelas JG (1999) The medial ganglionic eminence gives rise to a population of early neurons in the developing cerebral cortex. J Neurosci 19:7881-7888.

Luo L, Liao YJ, Jan LY, Jan YN (1994) Distinct morphogenetic functions of similar small GTPases: Drosophila Dracl is involved in axonal outgrowth and myoblast fusion. Genes Dev 8:1787-1802.

Malosio ML, Gilardelli D, Paris S, Albertinazzi C, de Curtis I (1997) Differential expression of distinct members of Rho family GTP-binding proteins during neuronal development: identification of Rac1B, a new neural-specific member of the family. J Neurosci 17:6717-6728.

Marin O, Rubenstein JL (2003) Cell migration in the forebrain. Annu Rev Neurosci 26:441-483.

Metin C, Baudoin JP, Rakic S, Parnavelas JG (2006) Cell and molecular mechanisms involved in the migration of cortical interneurons. Eur J Neurosci 23:894-900.

Molnar Z, Adams R, Blakemore C (1998) Mechanisms underlying the early establishment of thalamocortical connections in the rat. J Neurosci 18:5723-5745.

Moon SY, Zheng Y (2003) Rho GTPase-activating proteins in cell regulation. Trends Cell Biol 13:13-22.

Ng J, Nardine T, Harms M, Tzu J, Goldstein A, Sun Y, Dietzl G, Dickson BJ, Luo L (2002) Rac GTPases control axon growth, guidance and branching. Nature 416:442-447.

Nishimura T, Yamaguchi T, Kato K, Yoshizawa M, Nabeshima Y, Ohno S, Hoshino M, Kaibuchi K (2005) PAR-6-PAR-3 mediates Cdc42-induced Rac activation through the Rac GEFs STEF/Tiam1. Nat Cell Biol 7:270277.

Richards LJ, Plachez C, Ren T (2004) Mechanisms regulating the develop- ment of the corpus callosum and its agenesis in mouse and human. Clin Genet 66:276-289.

Ridley AJ, Paterson H, Johnston CL, Diekmann D, Hall A (1992) The small GTP-binding protein Rac regulates growth factor-induced membrane ruffling. Cell 70:401-410.

Raftopoulou M, Hall A (2004) Cell migration: Rho GTPases lead the way. Dev Biol 265:23-32.

Sarner S, Kozma R, Ahmed S, Lim L (2000) Phosphatidylinositol 3-kinase, Cdc42, and Racl act downstream of Ras in integrin-dependent neurite outgrowth in N1E-115 neuroblastoma cells. Mol Cell Biol 1: 158-172.

Serafini T, Colamarino SA, Leonardo ED, Wang H, Beddington R, Skarnes WC, Tessier-Lavigne M (1996) Netrin-1 is required for commissural axon guidance in the developing vertebrate nervous system. Cell 87:1001-1014.

Shekarabi M, Moore SW, Tritsch NX, Morris SJ, Bouchard JF, Kennedy TE (2005) Deleted in colorectal cancer binding netrin-1 mediates cell substrate adhesion and recruits Cdc42, Racl, Pak1, and N-WASP into an intracellular signaling complex that promotes growth cone expansion. J Neurosci 25:3132-3141.

Stenman J, Toresson H, Campbell K (2003) Identification of two distinct progenitor populations in the lateral ganglionic eminence: implications for striatal and olfactory bulb neurogenesis. J Neurosci 23:167-174.

Sugihara K, Nakatsuji N, Nakamura K, Nakao K, Hashimoto R, Otani H, Sakagami H, Kondo H, Nozawa S, Aiba A, Katsuki M (1998) Racl is required for the formation of three germ layers during gastrulation. Oncogene 17:3427-3433.

Toresson H, Campbell K (2001) A role for Gsh1 in the developing striatum and olfactory bulb of Gsh2 mutant mice. Development 128:4769-4780.

Toresson H, Mata de Urquiza A, Fagerstrom C, Perlmann T, Campbell K (1999) Retinoids are produced by glia in the lateral ganglionic eminence and regulate striatal neuron differentiation. Development 126:1317-1326

Wang L, Zheng Y (2007) Cell type-specific functions of Rho GTPases revealed by gene targeting in mice. Trends Cell Biol 17:58-64.

Watanabe T, Wang S, Noritake J, Sato K, Fukata M, Takefuji M, Nakagawa M, Izumi N, Akiyama T, Kaibuchi K (2004) Interaction with IQGAP1 links APC to Rac1, Cdc42, and actin filaments during cell polarization and migration. Dev Cell 7:871-883.

Wichterle H, Turnbull DH, Nery S, Fishell G, Alvarez-Buylla A (2001) In utero fate mapping reveals distinct migratory pathways and fates of neurons born in the mammalian basal forebrain. Development 128:3759-3771.

Wolfer DP, Henehan-Beatty A, Stoeckli ET, Sonderegger P, Lipp HP (1994) Distribution of TAG-1/axonin-1 in fibre tracts and migratory streams of the developing mouse nervous system. J Comp Neurol 345:1-32.

Woo S, Gomez TM (2006) Racl and RhoA promote neurite outgrowth through formation and stabilization of growth cone point contacts. J Neurosci 26:1418-1428.

Xu Q, Wonders CP, Anderson SA (2005) Sonic hedgehog maintains the identity of cortical interneuron progenitors in the ventral telencephalon. Development 132:4987-4998.

Zheng Y (2001) Dbl family guanine nucleotide exchange factors. Trends Biochem Sci 26:724-732. 